\title{
W ZWIĄZKU Z TEKSTEM R. BOROCHA
}

\section{A. Wspólczesna rewolucja obyczajowa}

\section{Problem przemian aksjologiczno-obyczajowych}

Półtora roku temu w „Edukacji Filozoficznej” ukazał się tekst mojego autorstwa ukazujący źródła dzisiejszych przemian obyczajowych. Artykuł zatytułowany Współczesna rewolucja obyczajowa ${ }^{1}$ mimo swej wagi teoretycznej nie doczekał się reakcji ze strony środowiska filozoficznego. A powinien. Na naszych oczach zachodzą wielkie zmiany, spostrzegamy je, krytykujemy. To, co 30 lat temu zdawało się żartem, dziś jest rzeczywistością․ Mimo tego nikt nie podejmuje sprawy ogólnie, z perspektywy filozofii dziejów. Problemem zajął się Bogusław Wolniewicz, ale ograniczył się do ustalenia faktu, że obywatele państw Zachodu dzielą się na „lewo-,, i „prawoskrętnych”3. Ci pierwsi byliby entuzjastami przemian, ci drudzy byliby im przeciwni. Przez dwa tysiące lat dominowali ,prawoskrętni”, teraz górę biorą „lewoskrętni”. Dlaczego tak się dzieje, nawet i on nie próbował wyjaśnić.

(Politycznie rozwiązaniem problemu nie jest zainteresowana ani tzw. prawica, ani tzw. lewica. Polityczna prawica woli ukryć źródła rewolucji

\footnotetext{
1 J. Stanisławek, Współczesna rewolucja obyczajowa, „Edukacja Filozoficzna” 2016, nr 62, s. 85-96.

2 Dla przykładu: „Małżeństwo obchodzi rocznicę. On: Popatrz kochanie, wszystko jak $w$ dniu naszego ślubu. Ona: Tylko dzieci starsze". Aby nie być gołosłownym: czołowy piłkarz niemiecki, Michael Ballack, w 2008 r. wstąpił w związek małżeński z kobietą, z którą miał już troje dzieci. (W 2012 rozwiedli się).

3 To odróżnienie i systematyczna krytyka „lewoskrętności” stały się podstawą popularności medialnej Wolniewicza.
} 
obyczajowej, a lewica swój udział w operacji zmiany świadomości mas. Obrońcy kapitalizmu propagują hedonistyczny system wartości, gdyż korzysta na nim gospodarka rynkowa. Entuzjaści lewicy, dziś anarchistycznej, nie zdają sobie sprawy, że wspierają kapitalizm. Naiwnie sądzą, że rewolucja obyczajowa przybliża ich do wymarzonego ustroju powszechnego szczęścia).

\section{Obiektywna przesłanka przemian: odwracalność nieszczęść ży- ciowych}

Zgodnie z naszym wyjaśnieniem siłą napędową przemian moralnych i obyczajowych jest postęp technologiczny i jego dwa następstwa. Po pierwsze, we współczesnym bogatym świecie nieszczęścia życiowe stają się odwracalne. Utrata nogi nie skutkuje jak przed wiekami biedą i poniewierką, gdyż skutecznie nogę potrafi zastąpić proteza. Choroba weneryczna przestała być wyrokiem: stosowna porcja antybiotyku w krótkim czasie usuwa zakażenie. Nie należy się dziwić, że obyczaje stają się swobodniejsze: obywatele zamożnych części świata mogą sobie dziś pozwolić na beztroskę w życiu.

Odwracalność nieszczęść życiowych stanowi przesłankę obiektywną przemian aksjologiczno-obyczajowych. Towarzyszy jest okoliczność subiektywna, zależna od ludzkiej woli: propaganda nowego systemu wartości. Tę aktywizuje sławna ,nadprodukcja”. Faktycznie nadprodukcji nie ma. Wytworzone towary w komplecie znajdą nabywców, o ile ci ostatni zostaną wyposażeni w stosowne środki finansowe. Ale nie są. Problem tkwi w nierównym rozdziale dochodów: jedni pieniędzy mają nad miarę i niewiele więcej potrzebują nad to, co posiadają (ileż można mieć jachtów albo odrzutowców?!); innymi ciągle brakuje. Z ochotą opróżniliby półki z zalegających je towarów, ale nie mają za co tego uczynić. To zjawisko 150 lat temu opisał Karol Marks.

\section{Przesłanka subiektywna: propaganda nowej aksjologii}

„Nadprodukcja” ma źródło dodatkowe. Jest nią skłonność do oszczędzania. Wyższa stopa życiowa nie implikuje automatycznie chęci nabywczej. Dawny ascetyczno-idealistyczny system wartości (a więc kultura 
tradycyjna) ze swej natury skłania ku tezauryzacji dochodów. To, co kiedyś było cnotą (zaoszczędzone pieniądze służyły akumulacji kapitału), dziś stało się grzechem. Dziś oszczędzanie pogłębia nierównowagę rynkową i tym samym utrudnia rozwój współczesnej gospodarki. Dziś cnotą jest wydawanie pieniędzy z uwagi na jej skutek, jakim jest tak potrzebne „nakręcanie koniunktury”.

Dawniej nierównowadze rynkowej przeciwdziałano poprzez: wiek XIX - otwieranie nowych rynków (Azja, Afryka), wiek XX - reklamę i kredyty bankowe (kredyty bankowe: transfer pieniędzy z portfeli ludzi bogatych do kieszeni osób gorzej zarabiających). Mimo tych zabiegów nierównowaga rynkowa pogłębia się z dziesięciolecia na dziesięciolecie. Konieczna stała się zmiana systemu wartości: likwidacja skłonności ascetycznych oraz idealistycznych i zastąpienie ich powszechnym hedonizmem.

Operacja przemiany aksjologicznej odbywa się za sprawą propagandy w środkach masowego przekazu oraz poprzez szkołę. Każda reklama oprócz zachwalania wybranego produktu zachęca do sprawianie sobie przyjemności. Szkoła przestała zmuszać do wysiłku.

Operacja przemiany aksjologicznej trwa od kilkudziesięciu lat. Pomimo krytyki i protestów działa skutecznie: w naszych czasach ludzie pieniędzmi szastają ${ }^{4}$. Dziś zarobią, jutro wydadzą, a jeśli im zabraknie, pożyczą. Krok po kroku do ich świadomości trafia przekonanie, że oszczędzanie nie ma sensu, gdyż żyje się tylko teraz, i nie ma sensu idealizm, gdyż ideały niczego konkretnego nie oferują. „Ważny jest poży-

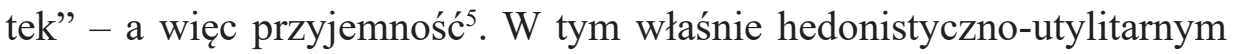

\footnotetext{
$4 \quad$ Wystarczy wejść do dowolnej kawiarni w centrum miasta. Do wydawania pieniędzy ludzi zmusza narzucony im styl życia. Kiedyś autor słyszał interesującą historię. Polskie małżeństwo trafiło do Australii. Tam mąż zrobił karierę i został kierownikiem filii (przedmieścia Melbourne) ważnej firmy. Po pewnym czasie awansował do centrali. Żona ucieszyła się, że nareszcie wyjdą z długów, jednak wkrótce okazało się, że długi wzrosły. Przecież „musieli” przenieść dzieci do lepszej szkoły, na wakacje nie jeździli już do Nowej Zelandii, a do Europy, kupowali ubrania renomowanych marek. Gdyby pozostali przy dawnym oszczędnym trybie życia, negatywna opinia o ich postawie szybko doprowadziłaby do zwolnienia męża z pracy. (To ostatnie jest domysłem autora). 5 Latwo teraz zrozumieć dystans, z jakim Unia Europejska odnosi się do chrześcijaństwa oraz pozorny socjalizm jej liderów. Chrześcijaństwo ze swym idealizmem i ascetyzmem nie jest prorynkowe, a obyczajowa swoboda nie przybliża komunizmu, a jedynie nakręca koniunkturę.
} 
duchu zdemolowano szkolnictwo: zniesiono kary (kary są tanie, nagrody kosztują), pilność i systematyczność (pilni i systematyczni w dorosłym życiu oszczędzają). Szkoła ma nie tyle uczyć - jak ta dawna, tradycyjna, co bawić6.

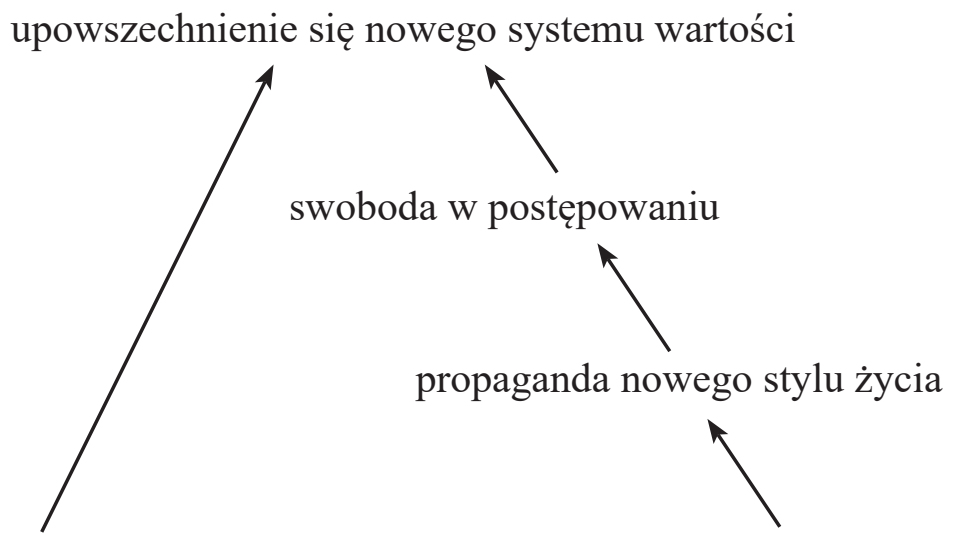

odwracalność nieszczęść życiowych pogłębienie się nierównowagi rynkowej

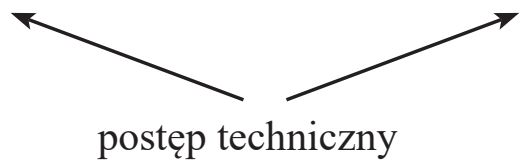

Rys. 1. Wspótczesny system wartości: źródła.

\section{4. Źródło popularności nowej aksjologii}

Nowa aksjologia (kultura współczesna, jak o niej mówimy we Wspótczesnej rewolucji obyczajowej): egalitarna, utylitarna i hedonistyczna, trafia do przekonania milionom ludziom, a trafia dlatego, że w każdym z nas drzemie egalitaryzm, utylitaryzm i przede wszystkim hedonizm. Masowa propaganda potrafiła zaktywować te barbarzyńskie składowe ludzkiej duszy - pozostałość po zwierzęcym rodowodzie człowieka. Przyjrzyjmy się jej działaniu na przykładzie współczesnej muzyki rozrywkowej.

\footnotetext{
6 Hasłem nowej szkoły powinno być „przez zabawę ku rozrzutności” (niektórzy chcą iść dalej: „przez zabawę ku rozpustności”), a nie, jak się głosi, „,przez zabawę do wiedzy”. Do wiedzy prowadzi nie zabawa, ale wielokrotne powtarzanie. A to nie jest ani zabawne, ani przyjemne.
} 
Muzyka pierwotna ma dwie składowe: rytm oraz brzmienie (barwę dźwięku) ${ }^{7}$. Melodia - od średniowiecza najważniejsza składowa utworu muzycznego ${ }^{8}$ - jest tworem Europy. W XX stuleciu muzyka klasyczna zamarła, ale wspaniale rozwinęła się muzyka rozrywkowa. Ale i to należy do przeszłości. Dziś króluje rytmiczny hard-rock (odpowiednik tam-tamów z tańców człowieka pierwotnego) oraz odpowiednik dźwiękowej barwy: utwory o niewyraźnej linii melodycznej, przetkanej szeleszczącym głosem solisty oraz dodatkami instrumentalnymi. Właśnie takie amelodyjne brzmienie dziś cieszy młodych ludzi. Tzw. przeboje czasem płyną w eter, ale te stare, z zeszłego stulecia. Nowych brak.

Barbarzyńska składowa duszy nastolatka zachwyca się hałaśliwym głośnym rytmem oraz owym nieuporządkowanym wieloinstrumentowym brzmieniem. Taką muzykę promuje dzisiaj Zachód.

\section{B. Tekst R. Borocha}

\section{Pseudopolemika}

W aktualnym numerze „Edukacja Filozoficzna” zamieszcza tekst autorstwa Roberta Borocha zatytułowany Współczesna rewolucja obyczajowa - czyli awantura o rock and rolla i bikini. Porównanie tekstu Borocha i artykułu Współczesna rewolucja obyczajowa (Boroch mój tekst nazywa skrótowo symbolem „WRO”; z uwagi na ten fakt pozwolę sobie jego tekst określić jako „BOR”) niesie niespodziankę: nie widać związku pomiędzy ich treścią. Wyjaśnienie tej rozbieżności jest trywialne: wbrew deklaracjom Borocha tekst jego autorstwa nie jest żadną polemiką z „WRO”, a jedynie rozważaniami poświęconymi czterem sprawom marginesowym: jednej istotnej (chociaż dla problemu źródeł współczesnej rewolucji obyczajowej drugoplanowej) i trzem marginalnym.

Historycy muzyki opowiadają, jak w okresie oświecenia do Francji przyjechał na zaproszenie hinduski maharadża. Zaprowadzono go na przedstawienie operowe. Po spektaklu ktoś zapytał, jak rzecz mu się podobała. Maharadża odpowiedział, że tylko jedna rzecz zrobiła na nim wrażenie. Która? To, co było na początku. Wejście solisty? Nie. Uwertura? Nie. Po długiej rozmowie udało się ustalić, że maharadża miał na myśli strojenie się orkiestry. (Rytmu tu nie było, ale urzekła go barwa dźwięku).

8 Od chorału gregoriańskiego (symbol: Veni Creator, IX wiek, kompozycja o pięknej linii melodycznej). 
„BOR” nie jest polemiką z „WRO” (już sam jego tytuł na to wskazuje), a jedynie autorskimi dywagacjami w sprawach ubocznych. Sprawy głównej: problemu źródeł współczesnych przemian aksjologicznoobyczajowych, Boroch nie podejmuje. Na kilkunastu stronach swego tekstu pisze o historii rock and rolla, o losach kobiet przed stu laty, o kulturze, ale ni słowem nie odnosi się do zasadniczych stwierdzeń zamieszczonych we Wspótczesnej rewolucji obyczajowej. Czy rację ma jej autor w swej diagnozie przyczyn przemian w świadomości społecznej, czy nie ma? Czy rzeczywiście u podłoża przemian tkwi potężna operacja propagandowa, czy też ,ludzie nareszcie zrozumieli, że oszczędzanie sensu nie ma"? Czy propaganda nowego systemu wartości faktycznie uruchamia tkwiące w ludziach pokłady barbarzyństwa? W sumie „BOR” jest tekstem nie na temat.

\section{Zarzuty R. Borocha: zarzut podstawowy}

W swoim wystąpieniu R. Boroch odnosi się do kilkanastu linijek Współczesnej rewolucji obyczajowej. Przytaczamy je w komplecie:

(a) Elitaryzm, idealizm i ascetyzm (wyznaczniki kultury tradycyjnej ${ }^{9}$ ) ustępują miejsce egalitaryzmowi, utylitaryzmowi i hedonizmowi. Kultura tradycyjna jako cel życia wskazuje realizację ideałów. Odpowiednio do stopnia realizacji ideałów ludzi uważa się tutaj za lepszych albo gorszych, a pohamowanie naturalnych skłonności stanowi powód do chwały. Kultura wspólczesna jako cel życia wskazuje doznawanie przyjemności. W jej ujęciu, podstawową wartością jest pożytek, a pożytkiem największym przyjemność osobista ${ }^{10}$.

(b) Ich początek [przemian w obszarze wartości i w obyczajach - J.S.] wyznacza pojawienie się rock and rolla oraz kostiumu bikini na plażach Atlantyku ${ }^{11}$.

(c) Weźmy za przykład los kobiety niezamężnej, która urodziła dziecko. Jeśli nie wsparła jej najbliższa rodzina... ${ }^{12}$.

Głównym zarzutem R. Borocha jest konstatacja, że w sprawach, o których mowa w przytoczonych zdaniach, autor Wspótczesnej rewolucji oby-

\footnotetext{
9 „Za Bogusławem Wolniewiczem”.

10 J. Stanisławek, dz. cyt., s. 85.

11 Tamże, s. 85.

12 Tamże, s. 87.
} 
czajowej nie rozważa obszernie (a) pojęcia kultury, (b) historii powstania muzyki rock and rolla i plażowych kostiumów dwuczęściowych, (c) losu kobiet przed stu laty. (W tej ostatniej sprawie czytamy np., że ,,autor ignoruje to, że sto lat temu... losy kobiet były zróżnicowane”, „nie precyzuje też, jakie kary społeczne były nakładane na kobiety z nieślubnymi dziećmi”, „nie uwzględnia problemu przemocy”"13. W sumie, Boroch ma pretensję, że autor Współczesnej rewolucji obyczajowej do swego artykułu nie wetknął traktatu na temat losu kobiet, które urodziły nieślubne dziecko).

Każda kwestia łączy się z wieloma innymi i autorowi każdego tekstu można zarzucić, że nie uwzględnił tej sprawy, tamtego artykułu, takich oto przykładów ${ }^{14}$. Boroch dostarcza przykładu kanonicznego. Gdyby wziął na warsztat tekst poświęcony zasadom dynamiki (np. Principia Mathematica Izaaka Newtona) w jego ,polemice” czytalibyśmy mniej więcej tak:

Rozważając zasady dynamiki Newton skupia się tylko na jednej sile. A przecież na każde ciało w każdej chwili działa wiele sił. Grawitacyjne, magnetyczne, siła tarcia, działanie jednostek albo grup ludzkich (np. w czasie zawodów w przeciąganiu liny). Skupia się na jednej okoliczności - a to w nieuprawniony sposób upraszcza rzeczywistość. Gdy ktoś pisze się o jakimkolwiek działaniu, powinien uwzględnić cały kontekst, jaki oddziaływaniu towarzyszy, zwłaszcza skutki, jakie fizykalna aktywność powoduje w otoczeniu: skutki realne i możliwe, i cały ciąg zdarzeń, jaki wystąpił albo mógł wystąpić1 ${ }^{15}$.

Boroch nie zdaje sobie sprawy, na czym polega idealizacja zjawisk rzeczywistych. Konkretyzm, jaki proponuje, ograniczyłby postęp wiedzy do spisywania szczegółów z życia osób, roślin, zwierząt oraz obiektów

\footnotetext{
13 Albo: „W przytoczonym fragmencie nie zostały podane dane faktograficzne $\mathrm{z}$ takich dziedzin jak demografia historyczna, socjologia społeczna, etnologia czy historia XX w.”. To trudne: zmieścić na dwu linijkach kilka książek. Biorąc szerzej: znowu zgodnie z życzeniem R. Borocha zamiast pisać artykuł o źródłach rewolucji obyczajowej, należałoby napisać całą książkę i to na inny temat.

14 Częste w recenzjach prac doktorskich. W pierwszej części swego omówienia recenzent wylicza, o czym doktorant napisał, a w drugiej, o czym nie napisał.

15 A owej hipotetycznej „polemice” towarzyszyłby zapewne mniej więcej taki przypis: „Zobacz w tej sprawie np. Power and Reality oraz Tug at the Time of Izaak Newton." [Takie dzieła raczej się nie pojawiły - J.S.].
} 
nieożywionych. W odniesieniu do osób znanych taką wiedzę przynoszą „Super Express” oraz „Życie na gorąco”.

\section{Zarzuty R. Borocha: zarzut oburzający}

Pomińmy impertynencję z zakończenia punktu 1.2.1'16 i zajmijmy się zarzutami dotyczącymi pojęcia kultury. We Współczesnej rewolucji obyczajowej mówi się o aksjologicznym pojęciu kultury (,kultura to zbiór wartości naczelnych"). Boroch tego nie zauważa. Posługuje się potocznym pojęciem kultury, zgodnie z którym kulturę tworzy wszystko, co niebiologiczne: moralność, obyczaje, sposób ubierania się itd. - i takie pojęcie imputuje artykułowi, z którym ,podejmuje polemikę”.

Z naszej charakterystyki kultury tradycyjnej oraz kultury współczesnej (zobacz pierwszy przytoczony fragment Współczesnej rewolucji obyczajowej) Boroch dedukuje w stylu „co autor miał na myśli”. Najpierw się domyśla (fałszywie), potem spekuluje (bezzasadnie), na koniec fantazjuje. Czytelnik dowiaduje się, że Stanisławek:

a) konstruuje opis kultury „w oparciu na dychotomii” (w naszym artykule dychotomii nie ma, są jedynie wskazane dwie odmienne formy kultury rozumianej aksjologicznie; z punktu widzenia logiki można mówić co najwyżej o przeciwieństwie),

b) wartościuje kultury (w artykule nie wartościujemy form kultury; zauważmy, że Boroch fakt owego wartościowania jedynie deklaruje, ale go nie pokazuje),

c) „powraca do etnocentrycznego rozumienia zjawisk kultury” (tu Boroch fantazjuje),

d) sięga po ,agresję antropologiczną” (fantazja Borocha staje się niebezpieczna) i oczywiście „pomija” wiele spraw szczegółowych.

Wszystkiemu towarzyszy symboliczne nazewnictwo. „Współczesna rewolucja obyczajowa" to $W R O$, kultura tradycyjna i kultura współczesna to $K_{T}$ i, odpowiednio, $K_{W}$ obyczaje tradycyjne i współczesne to $O_{T}$ oraz $O_{W^{*}}$ Czytać tego nie sposób.

16 „Proponowane w ramach WRO tezy są przykładem sofizmatu, który pozwolę sobie tu nazwać cock and bull story fallacy". 


\section{Kicz pseudonaukowy}

Pseudopolemika Borocha jest klarownym przykładem pseudonaukowego kiczu. Pozornie tekst dotyczy problemu, faktycznie odbiega od tematu. Sugeruje głębię analizy i śmiałość autora (słowo „awantura” w tytule, ostre słowa w tekście). Wszystkiemu towarzyszy uczona terminologia (,antropresja”, ,socjopresja”, „semiotyka antropologiczna”, „wielowymiarowe środowisko komunikacyjne”, ,parantele semiotyczno-semantyczne”, „,indeksowanie wyróżników obiektu”, „proces RAIS”) oraz liczne odwołania do piśmiennictwa w języku angielskim. Tak jak kicz malarski przypomina dzieło sztuki, tak tutaj kicz pseudonaukowy przypomina tekst z zakresu nauki.

W swój kicz Boroch wplata pseudonaukowy bełkot. Czytelnik spotka się z nim przede wszystkim w punkcie 2., zatytułowanym Uzupetnienie kontekstowe WRO - od etnocentryzmu do agresji antropologicznej. Do czasów Beethovena w koncertach skrzypcowych kompozytorzy pozostawiali niezapisany fragment nutowy - tak zwaną kadencję, który solista wirtuozowsko wypełniał własną inwencją twórczą, zwykle na motywach głównego tematu aktualnie odtwarzanej części utworu ${ }^{17}$. W tekście Borocha punkt 2. pełni funkcję kadencji. To tutaj na motywach naszego artykułu Boroch popisuje się swą uczonością. To tutaj zasypuje czytelnika niebanalnym słownictwem (np. „oddalenie generacyjne”, „redundancja informatyczna”, ,wymiar pionowy”, „wymiar poziomy”) i tytułami angielskich książek (choć żadnej nie cytuje). Bez potrzeby i bez związku z meritum funduje czytelnikowi kilka stron wykładu z zakresu socjologii $^{18}$.

Zwykły bełkot polega na tym, że nie rozumie się słów. Bełkot pseudouczony tym się różni od zwykłego, że słowa i zdania akapity są zrozumiałe, ale o czym autor informuje, nie wiadomo ${ }^{19}$. O czym pisze Boroch w punkcie 2. - i po co o tym pisze - trudno ustalić.

\footnotetext{
17 Od czasów Beethovena kompozytorzy zapisują kadencję w partyturze utworu.

18 Równie nieudany jest późniejszy nieudolny opis powstania muzyki rock and rolla.

19 To dokładnie jak w znanym dowcipie: „Do adwokata przychodzi mężczyzna i mówi, że chciałby się rozwieść. - Dlaczego, pyta adwokat. - Bo moja żona mówi i mówi. - A co mówi, dopytuje się adwokat. - Właśnie w tym rzecz, odpowiada klient”.
} 
Prezentacja tekstu R. Borocha jest interesującym eksperymentem na łamach „Edukacji Filozoficznej”. Czytelnik ma możliwość zetknięcia się z konkretnym przykładem pseudonaukowego kiczu wzbogaconego o pseudonaukowy bełkot, odniesienia się do niego, a także polemiki z krytyką przedstawioną w naszych uwagach ${ }^{20}$.

\section{Summary}

In the first part (A), the author refers to his article Contemporary Revolution of Customs ("Edukacja Filozoficzna", Vol. 62). In the second part (B), he refers to the text of Robert Boroch who criticizes the aforementioned article. Stanisławek believes that the criticism of Boroch concerns secondary matters, and that its author inaptly shows off, with information concerning the culture and history of popular music.

Key words: traditional culture, contemporary culture, moral changes, life misfortune, propaganda, false polemics, scientific kitsch.

Sprawy trafności przytoczonych przykładów (rock and roll oraz kostium bikini jako zwiastuny współczesnej rewolucji obyczajowe, stygmatyzacja kobiet, które urodziły nieślubne dziecko, jako przejaw funkcji ochronnej tradycyjnej obyczajowości) nie rozważamy. Po pierwsze, Boroch nie zakwestionował ich adekwatności (jedynie zalecił ich „,uzupełnienie faktograficzne”), po drugie, nie zaproponował dla nich zamienników. 